\title{
HANNAH ARENDT Y LUCE IRIGARAY: EL LENGUAJE DE LA PLURALIDAD Y LA INTERSUBJETIVIDAD EN LAS ESFERAS DE LO PÚBLICO Y LO PRIVADO ${ }^{1}$
}

\author{
Hannah Arendt and Luce Irigaray: \\ The language of plurality and the intersubjectivity in the public and the private spheres
}

María Cecilia Sánchez*

\begin{abstract}
RESUMEN
"Pluralidad" e "intersubjetividad" son palabras que definen el pensamiento de Hannah Arendt y Luce Irigaray. Más que configurarse como conceptos filosóficos, estas palabras buscan referir la trama de relaciones humanas (Arendt) o la relación entre hombres y mujeres diferentes (Irigaray), en esferas o zonas que permiten la mediación "yo/tú" y la revelación de un "quien" singularizado mediante la acción y el discurso. Darle curso a estas experiencias supone enfrentarse con uniformizaciones tiránicas y saberes que han priorizado a una humanidad fabricada por las ciencias naturales y sociales, dificultando el ejercicio de una democracia plural más que representacional. En este artículo me propongo comparar los planteamientos de las autoras mencionadas respecto de las tensiones entre prácticas relacionales y prácticas utilitarias de corte totalitario-patriarcal a las que se responsabiliza de poner en peligro o suprimir las relaciones entre ciudadanos/as y las relaciones de género como relaciones políticas.
\end{abstract}

Palabras clave: Pluralidad, intersubjetividad, lenguaje, fabricación, patriarcado.

\footnotetext{
${ }^{1}$ Este artículo se realizó bajo las coordenadas del Proyecto Fondecyt No 1130252, titulado: "El cuerpo, las pasiones y la política. Una lectura de la pluralidad y la intersubjetividad en Hannah Arendt y Luce Irigaray".

* Doctora en Filosofía, Universidad Paris 8 y en Literatura, Pontificia Universidad Católica de Chile [cotutela]. Académica e investigadora del Instituto de Humanidades, Universidad Academia de Humanismo Cristiano y Profesora en el Magíster de Estudios de Género y Cultura en CIEG, Universidad de Chile. Correo electrónico: cecisanchez0@gmail.com
}

Artículo recibido el 22 de abril de 2015. Aceptado el 01 de junio de 2015. 


\begin{abstract}
"Plurality" and "intersubjectivity" are words that define Hannah Arendt and Luce Irigaray's thinking. Rather than being conceived of as philosophical concepts, these words intend to relate the plot of human relationships (Arendt), or the relation between different men and women (Irigaray) in spheres or zones that allow the mediation "me/you" and the disclosure of a "who" singled out by the action and discourse. Enabling these experiences requires confrontation with tyrannical standardization and knowledge, which have prioritized a humanity fabricated by natural and social sciences, thus hindering the exercise of a pluralist instead of a representational democracy. In this article, I aim to compare the approaches of the previously mentioned authors regarding the tensions between political practices and utilitarian practices, the latter being considered responsible for endangering or suppressing both citizens relations and gender relations as political relations.
\end{abstract}

Keywords: Plurality, intersubjectivity, language, fabrication, patriarchy.

\title{
FUERA Y DENTRO DE LA VOZ DE LA FILOSOFÍA
}

¿En qué se asemejan Arendt e Irigaray? Adelanto que pueden llegar a ser sorprendentes las similitudes entre estas dos singulares pensadoras. La más evidente se advierte en la forma de interrogar políticamente las tradiciones del pensamiento filosófico para buscar claves de sentido que relacionen el pensamiento con la pluralidad (Arendt) y con la intersubjetividad (Irigaray).

Bajo el cometido de cuestionar al sujeto aislado y la estandarización de lo social y del espíritu, ambas autoras interrogan a la política desde el punto de vista de la relación con otros. Los significados de la pluralidad y la intersubjetividad, recogidos en diferentes períodos y tradiciones, es uno de los hilos que seguirá este artículo. ¿Por qué es oportuno hoy en Chile y Latinoamérica examinar el significado político de estas palabras? Mi respuesta inicial es porque los significados adscritos a lo privado y lo público, tal como se conocen, son insuficientes para detener la desintegración de la democracia según la conocemos hasta ahora, orientada a la fabricación y desatenta al lenguaje plural y a la diferencia. Asimismo, la separación abrupta entre ambas esferas facilita las violencias en contra de la alteridad y la diferencia. En la escena filosófica chilena, varios autores de relevancia se han hecho cargo de algunas de las temáticas sobre la política en el pensamiento de Hannah Arendt ${ }^{2}$. En mi caso, asumo el riesgo de intentar una lectura comparativa

\footnotetext{
${ }^{2}$ Patricia Bonzi y Cristina Hurtado son las primeras en incorporar el pensamiento de Arendt en el período de la dictadura. Posteriormente, su pensamiento es examinado por Carlos Ruiz, Marcos García de la Huerta, Felícitas Valenzuela, Carla Cordua, María José López, entre otros/otras.
} 
y diferenciadora entre dos autoras que han puesto el acento en lo humano desde el punto de vista relacional y juzgado con severidad las unificaciones que hacen perder la singularidad.

Para ingresar al pensamiento de Arendt, parto por señalar que las principales amenazas que se propone enfrentar son aquellas vehiculizadas por algunas de las concepciones modernas sobre lo social y por los totalitarismos, cuya principal meta ha sido producir una "humanidad fabricada" a partir de una idea. La preeminencia de la fabricación se encuentra primero en la concepción griega de la idea, de acuerdo a como Platón la desarrolla en la República y las Leyes; luego en el pensamiento cartesiano y en la filosofía política de Hobbes que después influye en el pensamiento evolucionista y las teorías modernas de la historia. Para evaluar estas concepciones unificadoras de lo humano, Arendt se sitúa en un "interregno", según señala en el Prefacio del libro Entre el pasado y el futuro. En esta "brecha", ella reconoce "cosas que ya no existen" y "cosas que aún no existen" (1996: 15). La habilidad para habitar en un "paralelogramo de fuerzas" en el que chocan las fuerzas del pasado y las del futuro la toma de un cuento de Kafka titulado Él.

Irigaray, por su parte, escribe para cuestionar el pensamiento patriarcal debido a su violencia y porque rechaza la diferencia para enfatizar la semejanza. En su caso, el antídoto ante tal amenaza es la posibilidad de desmontar o perturbar el lenguaje falocrático o logos filosófico que "reduce todo otro a la economía de lo Mismo" (2009: 55). En Arendt, lo político se concentra en la pluralidad del "estar juntos" que se priva de absorber o estandarizar al otro. En Irigaray, la construcción positiva de la diferencia en el marco de la "intersubjetividad" es la posibilitadora de lo múltiple. En suma, lo interrogado por las autoras son los supuestos filosóficos, teológicos, biológicos, económicos y psicológicos del humanismo que insiste en unificar lo humano bajo la expresión "el hombre" (Arendt) o del "Uno" (Irigaray).

Para examinar el problema de la uniformación de lo humano, ambas ocupan la voz de la filosofía sin identificarse del todo con ella. En su estudio sobre Irigaray, Judith Butler se pregunta si por el hecho de estar "en" esta voz (filosófica) también se puede estar "fuera" (Butler, 2005: 67). En el caso de Arendt, ante una pregunta de Günter Gauss en una conocida entrevista realizada el año 1964 acerca de su condición de filósofa, dice expresamente: "no pertenezco al círculo de los filósofos". No niega que se ha relacionado con esta disciplina, pero evita reconocerse como filósofa política en el horizonte de la institución platónica de la filosofía política, definida por su hostilidad a la ciudad. Según Miguel Abensour, Arendt postula que la hostilidad a la polis de parte de Platón y de la institución filosófica está marcada por el trauma de la muerte de Sócrates (Abensour, 2006: 31 32). A diferencia de Arendt, Irigaray intenta responder por qué lo que ella entiende por femenino está constitutivamente excluido de la filosofía, prevaleciendo de las mujeres una "mascarada" y toda suerte de revestimientos de su decir. En función 
de este ocultamiento, lee en la filosofía y en el psicoanálisis lo que no incluyen o suprimen. En especial, repara en los reversos, elipses y desviaciones de estos discursos.

Pese a su declarada incompatibilidad con la filosofía, al leer a Arendt es innegable el poderoso vínculo que mantiene con algunos aspectos de esta forma de pensamiento. En su comentario a esta pensadora, Étienne Tassin restablece el vínculo con la filosofía cuando señala que la originalidad de la reflexión arendtiana consiste en exigirle a la filosofía "una política del pensamiento", reformulando las condiciones de una filosofía que pueda, desde ese momento, llamarse "política": "no en razón de su objeto, sino en razón de su modo de pensar" (Tassin, 2001: 49).

Hasta aquí ambas autoras se muestran coincidentes en lo siguiente: rechazan unificaciones totalitarias y borramientos provocados por la teoría filosófica porque son fuentes de violencias, injusticias y de toda suerte de alienaciones. En un caso, la violencia y la alienación provienen del totalitarismo, la estandarización de lo social y el subjetivismo moderno. En el otro, la violencia y la alienación derivan del modelo abstracto de racionalidad que decreta funciones que capitalizan la vida y configuran relaciones según la estructura sujeto-objeto.

Desde el punto de vista de la relación entre lo público y lo privado, uno de los modelos unánimemente rechazados es el de la familia, debido a que construye parentescos que unifican lo diverso que, desde lo privado, se extrapolan al espacio público, a la par que el espacio doméstico se abandona a un empirismo carente de civilidad y de ética. El efecto que conlleva el modelo familiar para Arendt es el de arruinar la política. Cabe apreciar que la autora denuncia la equívoca prerrogativa de "refugio" o "alberge" que ofrece el modelo de la familia (Arendt, 2013). Irigaray también es especialmente crítica de la "inmediatez natural" en la que se funda el parentesco, cuyo modelo conduce a la fusión o borramiento de la diferencia en la esfera del amor (Irigaray, 1994: 38).

Pese a las concordancias mencionadas hasta el momento, uno de los contrastes entre ambas es con respecto al amor. Para Arendt es el espacio público el que debe resguardarse del peligro del totalitarismo que tiende a unificar y estandarizar lo humano a partir de la moderna concepción de lo social. En cambio, Irigaray presta una especial atención a la intimidad amorosa, sin descuidar la esfera de lo público. La esfera de las relaciones íntimas le interesa para transformar la relación entre hombres y mujeres entregada a la "incultura sexual" que conduce a la "alienación e injusticia" (Irigaray, 1994: 31-32). Por el contrario, Arendt no reconoce que pueda haber política en el amor. En uno de los párrafos La condición humana señala lo siguiente: "El amor, por su propia naturaleza, no es mundano, y por esta razón más que por su rareza no sólo es apolítico sino antipolítico, quizá la más poderosa de todas las fuerzas antipolíticas humanas" (Arendt, 2001: 261). 
Así planteados los temas, me interesa primero desarrollar algunos de los tópicos del pensamiento de Arendt sobre la pluralidad en pugna con la idea de fabricación de lo humano, propia del totalitarismo y del pensamiento moderno. Enseguida examino el punto de vista de Irigaray sobre la intersubjetividad y su crítica a la filosofía y al psicoanálisis. ¿Por qué compararlas? Porque aunque disienten en muchos aspectos, se asemejan cuando buscan corregir los presupuestos de lo que se ha entendido por público y privado. De estas esferas defienden la coexistencia y las interacciones humanas como única defensa ante las totalizaciones explicativas del Hombre del subjetivismo.

\section{EL LENGUAJE DE LA PLURALIDAD EN TENSIÓN CON LOS PROCESOS DE LA FABRICACIÓN}

Para indagar en el significado de la pluralidad en el pensamiento de Arendt es preciso reflexionar en torno a la multiplicación de los sentidos de la palabra "acción". En muchas ocasiones este término ha sido atacado por ocioso, inseguro, inútil e imprevisible, por este motivo es necesario rastrearlo en uno de sus principales libros, me refiero a La condición humana (1958). Sobre el sentido común que tiene como punto de referencia la pluralidad, tomo en cuenta las reformulaciones señaladas en La vida del espíritu (1978). El primero de estos libros ella misma lo traduce al alemán en 1960 bajo el título Vita Activa Oder Vom Tätigen Leben. Este título deja ver que el marco de la vita activa es "parte o la mitad de un todo complejo" (Jonas, 2000: 25), ya que, a diferencia del primero, el segundo libro mencionado alude a la vida pensativa.

Hablar del pensamiento político de Arendt supone explicitar sus modos de auscultar el lenguaje y los asentimientos o denegaciones hacia ciertas modalidades de escritura. Su opción por el punto de vista de la política la hace preferir el uso de un lenguaje común a todos; un lenguaje sensato que no provenga de un diálogo interior de la conciencia o de una coherencia con uno/a mismo/a, sino que del mundo o la ciudad. En ¿Qué es la política? establece la más paradójica de las adhesiones a la política cuando afirma que: "el hombre es a-político. La política nace en el Entre-los-hombres, por lo tanto completamente fuera del hombre" (Arendt, 2013: 46). En este pequeño párrafo están las bases de la distinción entre ser uno (el hombre) y ser varios (los hombres). Al aseverar que la política está fuera del hombre, confirma la instancia "extática" de quien está fuera de sí, dado que es mediante la acción que puede constituirse una "relación con" o un "entre" con seres únicos que se reconocen en sus iniciativas. Es importante en este punto hacer notar que la acción y el discurso revelan lo humano como singularidad y no meramente como ente que es parte de un proceso. El valor político asignado al lenguaje es 
incuestionable cuando se descarta que la política pueda realizarse como proceso impersonal o técnico. Sin embargo, tampoco se trata de lo personal o interno, ya que lo que tiene importancia política es el mundo, es decir, "el espacio entre", esfera donde tienen lugar los asuntos humanos (Arendt, 2013: 57).

Con todo, todavía no queda claro de qué sentido está dotado el mundo o "entre". La respuesta, reiterada en varios de sus libros y escritos, estriba en el milagro del nuevo comienzo. En relación al privilegio del inicio, al filósofo al que más aplaude es a San Agustín, quien asocia la palabra "initium" a la forma de existencia de los humanos en De civitate Dei XII. Sin embargo, al momento de comparar la fabricación (que procede del mundo técnico) con la acción que establece la realidad política como entre, Arendt escarba en la tradición griega y latina para buscar las palabras precisas que contengan la reserva de sentido de esta experiencia.

En La condición humana, algunas palabras claves de la política entendida como acción las encuentra primero en la expresión griega "archein" ("comenzar"), luego en las palabras latinas "agere" ("desencadenar un proceso" o poner en movimiento) y "gerere"("llevar"). El comienzo tiene el privilegio de iniciar o principiar una trama, aunque la continuación recae en los que llevan, ejecutan o realizan lo iniciado por uno. Al poner el acento en la relación cuando se habla de la acción, lo que queda en entredicho es que el actor sea plenamente un "agente", dado que en varios momentos es un "paciente". Esta doble situación de agente y paciente supone que hay un nexo entre política y sufrimiento debido a las consecuencias que desata el actuar de alguien. A diferencia del tirano o gobierno de un hombre que actúa en soledad para imponer un orden seguro, el actor es quien está en medio de otros y actúa sobre seres que son capaces de sus propias acciones cuando reaccionan. Por este motivo, el significado de la acción no se revela más que habiendo terminado.

Muy diferente es el caso de la fabricación, cuyo proceso es evaluado en referencia a un modelo previo. Tal es el caso de la concepción platónica de la política. A juicio de Arendt, Platón es ambiguo en la significación de la palabra "archein" al proponer en el Político y en las Leyes que el principiante se apropie de la acción que ha comenzado sin la ayuda de los demás (2001: 243-245). Dado que la política para Arendt en modo alguno puede entenderse como fabricación porque carece de un modelo previo, en el camino del actor necesariamente debe comparecer un narrador que se haga cargo del significado. Al respecto dirá:

Lo que el narrador cuenta ha de estar necesariamente oculto para el propio actor, al menos mientras realiza el acto o se halla atrapado en sus consecuencias, ya que para él la significación de su acto no está en la historia que sigue. Aunque las historias son los resultados inevitables de la acción, no es el actor, sino el narrador, quien capta y hace la historia (Arendt, 2001: 215). 
Para establecer la diferencia entre fabricación y acción, al igual que entre conocimiento y mando, Arendt necesita prestar atención al habla de la tradición porque permite comprender algunas escenas de la política y de la ciudad, pues en su reflexión también cuentan los límites o delimitaciones que interponen las "vallas" del jurista y las del arquitecto que operan como protección contra lo ilimitado de la acción. A diferencia del pensar metafísico, no busca en el lenguaje un buen origen o esencia que deba recuperarse. Al contrario, en la base de la política no hay más que pluralidad y, por lo tanto, nuevos comienzos; ello no obsta para "enmarcar" históricamente el lenguaje. El examen lingüístico es la única prueba que puede exhibir Arendt del origen político del lenguaje, fundado en experiencias y acciones concretas que dejan huellas en las palabras. A la inversa del pensamiento de Platón y sus esquemas utópicos, la política para Arendt se centra en la doxa y no en la aletheia ${ }^{3}$. Esta preferencia explica su cercanía con la sofística y la retórica en desmedro de la filosofía. Como bien señala Seyla Benhabib (1992), su pensamiento se centra en las "capas de lenguaje" (108) con las que se configura la doxa política que permite hacer cosas y no solo transmitir algo verdadero. En cierto modo, podría decirse que el lenguaje es el único testigo de las mutaciones de la vida humana y de sus anuncios. Por lo mismo, pensar la política consiste en rememorar o narrar los significados del lenguaje en el horizonte de las diferentes tradiciones examinadas, entendiendo que entre unas y otras hay rupturas de sentido, también equivalencias y nuevos contextos que permiten a las palabras antiguas renovar su sentido al manifestarse en un horizonte determinado. Este procedimiento es muy evidente en La condición humana, abocada a la reflexión de las tres palabras que configuran la vita activa, a saber: la "labor", el "trabajo" y la "acción" detalle en su decir, el concepto que comanda su indagación es el "espacio público", caracterizado como una segunda vida o bios politikos, apartada del parentesco, de acuerdo a las demarcaciones establecidas por Aristóteles. Inicialmente se trata de una figura topográfica del habla (lexis) y de la acción (praxis): la "polis competitiva", como la llama Benhabib (1992:109), pero también habita en su pensamiento el espacio público que no es topográfico ni institucional, sino el espacio donde se actúa de modo concertado que Benhabib denomina "asociativo" (2000: 111)5. Ambas

\footnotetext{
${ }^{3}$ Desde el esquema de la fabricación, uno de los libros de Platón más criticado por Arendt es la República porque las ideas que aplica el filósofo-rey para hacer la polis son análogas a los modelos usados por el artesano para fabricar un objeto.

${ }^{4}$ De modo prioritario, en La condición humana Arendt interroga a las tradiciones que se expresan en la vita activa para enjuiciar la tradicional jerarquía que hizo prevalecer a la contemplación por sobre las inquietudes del trabajo, los actos y las palabras.

${ }^{5}$ Según Seyla Benhabib, el modelo "agonista" del espacio público es el legado de la "estudiante de la filosofía alemana fenomenológica y existencialista", mientras que el legado "asociativo" es el legado de la "modernista" y la "judía alemana" que encuentra protección en Estados Unidos (2000: 113).
} 
modalidades del espacio público contrastan con el espacio del totalitarismo, cuya topología es descrita en Los origenes del totalitarismo como un vasto espacio que suple las "fronteras" o "cercas" que permite relacionar a los individuos para poner en su lugar un "anillo de hierro" que los funde en un todo, según denomina a la topografía totalitaria. En el espacio político existe el reconocimiento a la acción y al discurso con-los-otros, a diferencia del totalitarismo que busca la unificación o fabricación del Hombre en virtud de un fin planificado. Arendt advierte que el totalitarismo no carece de ley: al contrario, busca legitimarse recurriendo a una justicia cuya ley viene de la "historia" (Stalin) o de la "naturaleza" (Hitler). En el caso de los nazis, la legalidad se toma de las teorías evolutivas de Darwin, con el propósito de producir a la Humanidad como su "producto final" (Arendt, 1994: 561).

El término que ayuda a comprender el "entre" o "con- los- otros" de la pluralidad es el mundo, entendido en cierto modo desde la preposición "con". A propósito del "con", se puede preguntar cuánto le debe Arendt al planteamiento de Heidegger del "ser -en -el mundo", orientado a enfatizar la filosofía como metafísica explícita o como ontología fundamental, abandonando la filosofía de Platón y Aristóteles que proponen la physis como idea que tiene como efecto el sometimiento del ser al pensamiento (Dastur, 1972). En esta perspectiva, el Dasein ocupa en el pensamiento de Heidegger un lugar privilegiado para desplazar el predominio científico-técnico. Por su diferencia ontológica, el Dasein es apertura al ser y no puede ser objetivado en propiedades sustantivas. En Ser y tiempo, Heidegger asocia el Dasein al "co-estar" o estar con otros (Heidegger, 2005: 139154). En su lectura de Heidegger, Valentina Bulo problematiza esta asociación, debido a que el análisis desarrollado por Heidegger describe primero a un "solitario Dasein" para, posteriormente, incorporar el momento co-originario vuelto a los otros (Bulo, 2012: 113). Jean Luc Nancy señala que la ontología heideggeriana del Mitsein (ser-con) es un esbozo en el que no vuelve a insistir (Nancy, 2006: 74). En las definiciones de lo social de las ciencias sociales, la preposición "con" sigue entendiendo el "conjunto" como "yuxtaposición partes extra partes": es decir, partes aisladas carentes de relación, similar a una colección que produce agrupamientos desde el exterior, ignorando la posibilidad del estar juntos. En el caso de Arendt, podría decirse que la preposición "con" en su sentido temporal es uno de los logros de su pensamiento para pensar un nexo relacional y no físico. Irigaray trata de pensar este "con" como una posición que invalida la plenitud de sentido de todo sujeto o individuo para hacer aparecer la diferencia que impide la apropiación del otro.

Otro aspecto del mundo es que permite interactuar en una temporalidad común mediante lenguajes persuasivos para de ese modo aparecer ante otros a partir de cualidades que otros ven. Por el contrario, estar fuera del mundo se asemeja a la experiencia del "paria" que en el totalitarismo corresponde a la gente sin Estado 
y sin mundo común que se encuentra privada de realidad. De este modo, quien actúa vive bien porque adquiere un daimon. Esta es una palabra griega que Arendt busca recuperar porque se encuentra en la base de su definición de lo humano, ya no como naturaleza ni como figura de intercambio en una sociedad comercial, sino como la "esencia" del aparecer de "quien es alguien" (2001: 216) porque nace a la vida en un sentido político y no solo fisiológico. Desde el punto de vista griego, esta esencia es la "identidad" de quien deja tras de sí una historia en la polis o mundo. Se trata de la "fama inmortal" de quien arriesga la vida porque pudiera no sobrevivir a su acto, como fue el caso de Aquiles. Paradójicamente, la eudaimonia que consiste en "vivir bien", a veces se adquiere al precio de la vida. Pero el acto mortal necesita, como todo acto político, de una narración que lo signifique. El poeta, narrador o escritor es necesariamente quien consagra como político o significativo un acto que, por su fugacidad, podría haber quedado como fútil.

Si bien, como se ha visto, el contrapunto en el que más insiste Arendt es entre el hacer político cuyo hacer es relacional y el homo faber cuya producción se mide por su producto final, también se preocupa de establecer los nexos entre el artista y el trabajador. Para abordar este nexo, toma en cuenta la protesta de los artistas de comienzos del siglo XX contra el rótulo de "genios" para identificarse con el trabajador. En épocas anteriores, al genio se lo reconoció por dar curso a la aparición de un estilo, ya que de ese modo su producción repercutía en el quien es del artista, entrando a depender de su talento. En cambio, el hacer de la política, en comparación con el trabajo como actividad, es dadora de esencia, por así decirlo. La diferencia es aún más radical en el caso del laborante, pues aunque se reúna en grandes grupos carece por completo de individualidad o de identidad debido a sus experiencias somáticas y a su producción de valores sociales. Por su uniformidad, esta unión de muchos es entendida como antipolítica, a diferencia de la comunidad que se reúne mediante la acción y el discurso. En este punto conviene hacer una distinción importante de comprender hoy en día en Chile en torno a los significados de la igualdad y la uniformidad. Para Arendt, la igualdad política es diferente de la igualdad que invoca la cristiandad ante Dios o de la igualdad ante la muerte. En ambos ejemplos, la igualdad es uniformidad no mundana porque no se necesita de otros para que ocurra. En cambio, la igualdad política es la igualdad de los desiguales que necesitan ser igualados para fines específicos. El factor igualador es así político y en modo alguno puede ser natural o social.

Por su importancia, cabe detenerse en un último aspecto de la acción que la liga de modo definitivo a la presencia de los demás. Dado que los asuntos humanos son frágiles e inseguros, su perduración depende de una red de relaciones humanas que relativiza la autonomía y la soberanía humana fundada en el dominio del yo. Si bien la dependencia con los otros es la que debilita la pluralidad porque no permite predecir o saber por completo lo que se hace, uno de los remedios ante lo 
imprevisible de los actos humanos lo encuentra Arendt en la facultad de perdonar $\mathrm{y}$ de hacer promesas. Perdonar y prometer son actos que funcionan en conjunto. La primera facultad deshace los actos del pasado, lo que confirma que la acción jamás podría quedar reducida a un solo acto. La segunda entrega cierta seguridad en el contexto que, por definición, es inseguro. Según puede advertirse, Arendt seculariza el perdón proveniente del contexto cristiano, asociado a la figura de Jesús de Nazaret, pese a que la conexión con el amor pone en duda su relación con la esfera pública. Aunque un poco al pasar, en este parágrafo también considera lo "imperdonable" a partir de lo que Kant denomina "mal radical". Como se sabe, sobre esta experiencia en la era de los genocidios y su cambio de opinión sobre lo que se ha entendido como "mal" hablará en Eichmann en Jerusalén ${ }^{6}$.

En el caso de la promesa y su poder vinculante de actuar de común acuerdo, el contexto invocado es el poder de pactar alianzas, asociado a Abraham y al sistema legal romano. En el marco de la filosofía, cita a Nietzsche, autor de La genealogía de la moral, para cuestionar algunas de sus aseveraciones sobre el acto de hacer promesas. En el caso de este autor, la promesa es la "memoria de la voluntad" y fija la frontera entre lo humano y lo animal. Sin embargo, la importancia política que le concede Arendt al prometer y al perdonar se debe a que ambas surgen, no de un aprendizaje de modelos de moralidad, sino del hecho mismo del vivir juntos bajo la impronta de actuar y de hablar. Estas cualidades "psicopolíticas", como las llama Kristeva (2003), son las que rompen o interrumpen causalidades automáticas, necesidades, biologicismos o predestinaciones de los asuntos humanos. Debido a esta posibilidad de interrupción que el perdón ejerce sobre legalidades o procesos inexorables, se convierte, para Arendt, en "la única facultad humana de hacer milagros" (Arendt, 2001: 266).

Con el perdón y la promesa la política deja de ser pensada al modo griego e incorpora una relación con el tiempo que pueda subsanar la fugacidad o fragilidad de los asuntos humanos. A la inversa de lo propuesto por Nietzsche, para quien la promesa es una forma de carga o deuda introducida por el aprendizaje violento de una memoria que se proyecta al futuro, Arendt repara en su poder estabilizador a nivel de las relaciones y de las incertidumbres del futuro. Esta garantía, por cierto, es limitada: de allí los tratados y contratos. Lo importante de la promesa es que garantiza una forma de vínculo basado en la reciprocidad. La tradición a partir de la cual piensa los contratos o pactos es la de los romanos. En cuanto a la reciprocidad que ofrecen las alianzas, piensa en Abraham. Estas dos vertientes, incluido el perdón, son prácticas colectivas de carácter religioso. En su caso, el

\footnotetext{
${ }^{6}$ Brevemente, digamos que a propósito del juicio a Eichmann, en vez de calificar de "mal radical" o "absoluto" los crímenes en los campos de exterminio, Arendt hablará de "banalidad del mal" para referirse a la degradación de los seres humanos llevada a cabo por el totalitarismo.
} 
marco político en el que las incluye es el de la pluralidad humana, en la medida en que no hay perdón ni promesa en soledad.

Además de su significado religioso, el perdón y la promesa ponen a prueba el acto comunitario del lenguaje y el del sentido común o "sensus communis" por el que aboga permanentemente la autora para hacer prevalecer lo provisional en vez de la fabricación y de las certezas cognitivas. De este modo, el milagro mencionado más arriba depende de este acto intersubjetivo o plural que apela al otro, como bien señalan Humberto Giannini y María José López en su artículo sobre la promesa y la política (2014). Giannini y López arrancan su reflexión citando a Husserl para caracterizar la relación indirecta que tenemos con el otro porque no vivimos directamente su experiencia. De allí que la posibilidad de estar en "lo mismo" depende de una "confesión" (Giannini y López, 2014: 64 - 65), de un acto de habla que supone la intuición de la vivencia del otro, llegando a la interrelación. ¿Qué pasa con la promesa? Tomando el punto de vista de Arendt (también dialogan con Derrida), los autores valoran del acto de la promesa el hecho de apartarnos de lo fáctico y del tipo de interés que conlleva, porque sin bien le otorga al otro el poder de cobrarla, no se trata del interés concebido como "beneficio" en el marco de un intercambio que exige cálculo. Al contrario, la promesa tiene un carácter gratuito equivalente a un don, por lo que "responde a la raíz de la palabra inter-esse" (69). Para Arendt, el inter-esse es un vínculo plural facilitado por el hablarse entre dos o más.

\section{LAS PASIONES, EL SENTIDO COMÚN Y LA CAVERNA DE PLATÓN}

De acuerdo a lo dicho hasta el momento, una comunidad no puede ser otra cosa más que una comunidad de lenguaje que nos hace vivir en la realidad del mundo. Por esta razón, una comunidad política no puede ser ni familiar ni teórica ni social. Asimismo, el lenguaje que se encuentra en juego no es utilitario ni cognitivo en el sentido del know-how, sino que es el discurso que permite encontrar las palabras y poder persuadir para permanecer con los otros al margen de la mudez de la violencia. Refiriéndose a la época moderna, lo que rechaza Arendt son las conductas uniformes o conductas sociales que dejan sin efecto el proceder de la comunidad de lenguaje porque nos remite a procesos puramente vitales.

Si bien se puede estar de acuerdo en que la pluralidad es de suma importancia en la esfera pública, en lo que viene del artículo postulo a partir de Irigaray que también se la necesita en la esfera íntima. Arendt es sumamente crítica para aceptar la pluralidad en la vida íntima, habitada por las pasiones del corazón, los pensamientos de la mente o los placeres sensoriales: a todos los tacha de "inapropiados" porque carecen de un lenguaje singularizador. Una "forma adecuada para la aparición pública” admitida por Arendt es la "narración de historias" (2001: 
59). Es decir, convertir las experiencias subjetivas en algo digno de verse u oírse en público. Cuando eso no es posible, las pequeñas cosas del mundo íntimo se deben vivir dentro de "sus cuatro paredes" o en la esfera del corazón. De esta manera, Arendt opone el "encanto" de lo privado a la "grandeza" del mundo común.

En La vida del espiritu las pasiones nuevamente son mencionadas para discernir si se trata de una actividad propia del espíritu o si son reacciones externas. Esta vez advierte que su origen no es subjetivo, ya que se expresan o saltan a la vista corporalmente como "sonrojo" o "palidez", también mediante una felicidad que nos hace "brillar" o "desanimarnos". En todos estos casos es el cuerpo el que nos delata cuando no hemos desarrollado un severo autocontrol. La diferencia con el rechazo a las pasiones en La condición humana es su lectura de la Crítica de la razón pura de Kant, en donde advierte que estos humores o estados de ánimo no tienen un origen interno, ya que son "suscitadas por acontecimientos externos que afectan el alma y ocasionan determinadas reacciones" (Arendt, 1984: 91). Esta nueva apreciación permite abrir la pregunta por la relación entre acontecimientos políticos y cuerpo. Por cierto, el desarrollo más extenso de este examen lo dejo para un próximo artículo sobre el pensamiento de Arendt e Irigaray.

La preocupación por las pasiones se debe a su necesidad de poder diferenciar las relaciones entre humanos de lo interno de los sentimientos y de lo fusionado de la sociedad o de la familia. Para Arendt, la comunidad que está en el mundo mantiene un nexo. Para ser mundano, este nexo debe rechazar una relación de carácter íntimo o fraterno. Para la defensa del aspecto separador del mundo común Arendt discute con la tradición cristiana y su ideal de fusión de un cuerpo comunitario. Pero la discusión más fuerte la tiene con Descartes, a quien acusa de ser el responsable de la pérdida del "sentido común" al sustituirlo por la introspección. Para Descartes, se trata de la experiencia que encontramos en los "procesos" de la conciencia. Estos procesos o movimientos permiten mayores certezas porque provienen de la mente deductiva o matemática en vez de los sentidos que pueden engañarnos. Desde estos parámetros, la matematización física es la realidad en un sentido moderno porque surge de la subjetividad humana, en la medida en que de hipótesis pasa a ser una realidad creada desde la mente. Según Arendt, bajo el modelo del pensamiento moderno el hombre se convierte en un productor y fabricador. Ante todo, le preocupa el "cómo", el "proceso" de los objetos de las ciencias naturales o el "desarrollo" al que atienden las ciencias históricas. Incluso, teme que las pasiones, que también forman parte de la subjetividad humana, puedan llegar a ser usadas para crear un "autómata" u "hombre artificial", como es el "gran Leviatán de Hobbes", quien introduce los conceptos del fabricar y el calcular para aplicarlos a la filosofía política.

La fabricación es para Arendt una de las más temidas posibilidades humanas porque está a la base de todos los totalitarismos. En vez de la política que es capaz 
de lidiar con lo inesperado, la fabricación puede calcular las consecuencias. Si, como señala Arendt, la acción se convierte en fabricación en la época moderna debido a la pérdida de mundo y del sentido de realidad que entregaba el sentido común, entonces ¿qué es posible entender por sentido común? En La condición humana se lo define como el sentido humano de la realidad; una cualidad política que "encaja como un todo en la realidad de nuestros cinco sentidos estrictamente individuales y los datos exclusivamente individuales que capta" (Arendt, 2001: 231). El problema es cuando el sentido común se debilita porque surge el aislamiento de lo que no es confirmado por los demás. Arendt advierte que a esta falta de relación con los demás en las relaciones comerciales y de consumo Marx la llamó "deshumanización” o "autoalienación” (232). Esta deshumanización tuvo como efecto que la grandeza y la singularización humana solo podía aparecer en lo privado familiar, en la intimidad con los amigos, desapareciendo de la esfera pública.

A lo largo de La condición humana el sentido común es mencionado varias veces, pero una mejor aproximación al término se puede leer en La vida del Espíritu. En compañía de Kant, Husserl y Merleau-Ponty, la autora lo aborda a propósito de su opuesto: el solipsismo. El filósofo más criticado en este sentido sigue siendo Descartes, quien hace la experiencia del fingimiento metódico de estar solo en el mundo y de no tener un cuerpo para fundar su certeza del ego sum. Por el contrario, el sentido común, denominado "sensus communis" a partir de Santo Tomás en la Summa Theologica, es un sexto sentido o sentido interno que actúa como raíz común de los otros cinco sentidos que tienen un carácter privado. Su virtud es la de salvarnos de la mera sensitividad por el hecho de que el objeto también aparece ante otros de modo intersubjetivo. Así, en vez del acto subjetivo del pensamiento puro, el sentido común se orienta a un "objeto común". Para Arendt, lo común significa que:

los individuos de la misma especie comparten un contexto común que le confiere a cada objeto en particular su propio significado; y todos los demás seres dotados de sentidos, a pesar de percibir el mismo objeto desde perspectivas completamente distintas, están de acuerdo en cuanto a su identidad. La sensación de realidad surge de esta triple afinidad (Arendt, 1984: 67).

De este modo, la sensación de realidad defendida en contra del subjetivismo es la del "estar ahí". Se trata del "contexto" en el que aparece cada objeto en particular. Según Arendt, los filósofos profesionales prefieren la supresión de este sentido para pensar. En la historia de la filosofía, quienes se apartan de los otros y del mundo para acogerse a la compañía de los muy pocos o a la absoluta soledad se puede pesquisar desde Parménides y Platón, encantados con la belleza del Kosmos, hasta 
la autosuficiencia del ego de la filosofía moderna con Descartes, cuya característica es no depender de una ubicación ni del cuerpo ni del mundo en general.

En su crítica al solipsismo y a la tradicional distracción respecto del mundo, insiste a menudo en que es equivalente a la antigua afinidad entre muerte y filosofía. Desde Platón a Heidegger -este último especialmente entiende la anticipación a la muerte como una experiencia decisiva para alcanzar la autenticidad- los filósofos se han visto tentados a disociar el alma del cuerpo, buscando retiros que Arendt lee en clave platónica como una salida de la caverna -el lugar de la multitud-al cielo de las ideas; suerte de destierro que despierta la risa de la multitud. Cabe recordar que una mujer, la joven Tracia, es quien se echa a reír al ver a Tales que, al mirar el movimiento de los cuerpos celestes, cae en un pozo. En su comentario a esta vieja leyenda, Platón, en el Teeteto, 174a-d, se reconoce en Tales diciendo: "cualquiera que entrega su vida a la filosofía está expuesto a tal escarnio".

Si para Arendt la caverna es el lugar del que el filósofo se aleja por ser el lugar del sentido común o doxa, para Irigaray este mito pone en escena la metáfora de la "matriz" o "vientre" (2007: 221), desde la cual se proyectan los hombres encadenados hacia el mundo de arriba o mundo de la verdad. La caverna representa el mundo de las sombras, pero orientado a lo que está por delante. En su libro Espéculo de la otra mujer, esta sería la ficción de la "perspectiva rectilínea" o de la "dirección fálica". La puesta en escena de estas metáforas y las referencias críticas a Platón por parte de Irigaray son para enjuiciar el orden falocrático de la filosofía. En el orden de lo que entiende por "ideología patriarcal", también enjuicia en este libro la teoría de la sexualidad de Freud. Estas referencias son de suma importancia para examinar sus críticas y propuestas de una ética de la diferencia sexual que hace de la intersubjetividad un imperativo tanto en la esfera pública como en la privada.

\section{LUCE IRIGARAY: LOS PASADIZOS DE LA CAVERNA DE PLATÓN}

Luce Irigaray, conocida como "la filósofa de la diferencia sexual más importante del siglo XX (Birulés y Fuster, 2010: 13), desarrolla un extenso examen crítico acerca del "falocratismo" o pensamiento del Uno, cuyos principales representantes son Platón y Freud. En libros posteriores sus críticas recaen en el pensamiento de Hegel. El examen inicial de falocratismo o ideología patriarcal forma parte de su libro Espéculo de la otra mujer, publicado por primera vez en 1974. Se trata de su tesis doctoral, cuya clave de lectura está regida por la metáfora del espéculo. Su denuncia es hacia lo que el patriarcalismo psicoanalítico y el filosófico han pretendido esconder bajo la perspectiva de una universalidad neutra que encubre la diferencia entre los sexos e impide la intersubjetividad. En su comentario a Irigaray, Judith Butler hará ver que el pensamiento de Irigaray 
es sumiso a las convenciones heterosexuales al afirmar que solo lo femenino se encuentra en la esfera de lo excluido (Butler, 2005: 85).

Para la investigación sobre la pluralidad y la intersubjetividad en lo público y lo privado, resulta importante considerar la perspectiva de Irigaray porque su pensamiento busca resaltar política y culturalmente la validez de la diferencia sexual en ambas esferas, en contra del predominio de una sociedad regida por un sujeto neutro en lo público. Esta es la gran diferencia con el pensamiento de Arendt, para quien el espacio público es el único en el que puede desplegarse la pluralidad. Bajo la noción de ética, Irigaray exige reconocimiento de la diferencia y de la intersubjetividad entre hombres y mujeres, hasta el momento denegada debido al predominio del sujeto único. Con el propósito de comprender lo que en varios de sus libros ella denomina "ideología del Uno" o de lo "Mismo", me propongo examinar en Espéculo de la otra mujer su lectura crítica de la caverna de Platón y la interpretación de la femineidad por parte de Freud. Posteriormente, me refiero a las críticas al patriarcalismo de Hegel y su reivindicación de la ética en Amo a ti. Bosquejo de una felicidad en la historia.

En el caso de su lectura de Platón, un aspecto de su examen psicoanalítico recae en los simbolismos que encierra el mito de la caverna, caracterizado como un lugar en sombras en oposición al mundo de la luz. Desde tal perspectiva, la metaforicidad de la sombra que trabaja Platón en la caverna Irigaray la hace equivalente a una "vagina olvidada", entendiendo que para el filósofo griego este es el mundo que debe descartarse para ascender al mundo de la verdad como desocultación (Irigaray, 2007: 237). Como se verá, Irigaray le presta atención al "corredor" o "pasadizo" entre un afuera y un adentro de la caverna, símbolo de la cavidad uterina, referida por Platón como un conflicto entre la luz blanca de la verdad y el negro que carece de verdad. Por lo tanto, se trata de dos escenas articuladas por la imagen de un pasadizo que debe cruzarse en una recta dirección; suerte de "parto" donde Sócrates es la figura que hace de partero e instructor para ascender a la verdad, a la "eterna presencia" que Arendt denomina "la eternidad del kosmos". Desde estas imágenes, el relato es sobre el "re-co-n(a/o)cimiento de la verdad" (240). Es importante recalcar que la representación de la verdad se encuentra dominada por la "semejanza", a diferencia de lo materno de la caverna representado como el lugar de las dobles copias, de lo amorfo o velado ${ }^{7}$. En este sentido, la verdad se escenifica en la economía fálica de la desocultación, equivalente a levantarse o ponerse en posición vertical, además de buscar coincidir con el logos y la lógica de la filosofía. Con todo, este paso de un mundo a otro ejecutado por los prisioneros de la caverna, una vez convertidos a la causa de la verdad contiene

${ }^{7}$ La concepción de lo femenino como "materia-soporte", la examina Irigaray en su lectura del Timeo de Platón en Espéculo. 
un momento de sufrimiento, ya que son afectados de "afasia" o "mudez" porque todavía no saben decir lo que se "debe decir" (Irigaray, 2007: 246).

En La condición humana, Arendt examina el vínculo entre teoría y asombro (thaumazein), advirtiendo que la contemplación de la verdad produce la experiencia del "pasmo" o inmovilidad del cuerpo mientras el filósofo se encuentra absorto en sus pensamientos. Al igual que Irigaray, la autora judía-alemana también menciona el "estado de mutismo" que afecta a quien contempla (Arendt, 2001: 327-328). Sin embargo, Arendt llega más lejos que Irigaray cuando dice que el comienzo de la filosofía y también su cumplimiento generan un mudo pasmo. En La vida del espiritu, señala que este problema con el lenguaje es uno de los efectos de la pérdida del sentido común, debido a que cuando ocurre adviene el "despiste" que es propio, dirá, del pensador profesional (Arendt, 1984: 70).

Desde el esquema de la caverna elaborado por Platón, Irigaray dirá que, tras la mudez que produce la contemplación, lo que adviene es un "(re)aprender a hablar" para distinguir y nombrar con arreglo a una ley que recusa las certidumbres sensibles de la doxa (Irigaray, 2007: 247). En el nuevo discurso de la verdad, el habla de la pasión que proviene de la fantasmática de la caverna se proscribe. En estas dos formas de hablar (el habla de la pasión y el de la verdad) Irigaray encuentra la diferencia entre lo paterno y lo materno que se mantiene o "trabaja" al interior del discurso de lo Mismo o lo verdadero. En textos posteriores, la diferencia ya no se plantea desde lo paterno y lo materno, sino que desde la singularización que permite la intersubjetividad. Por el momento, las metáforas que comparecen en su texto obedecen a la escena o "mimodrama", según la llama, del alumbramiento de un niño o aprendiz de filósofo, quien debe olvidar su relación con lo matricial para poder tener un alma especulativa. En comparación con el receptáculo materno, el padre es pura especularización irrepresentable, inundación de luz que aniquila la mirada empírica.

\section{LA CONVERSIÓN DE LAS MUJERES Y LOS HOMBRES EN “NORMALES”}

Además de la escenificación filosófica de lo Mismo (semejanza) en su lectura del mito de la caverna de Platón, en Espéculo la autora discute con la escena psicoanalítica que desvaloriza a las mujeres a partir del curioso texto que Freud redactó tardíamente y tituló "La feminidad". Se trata de una conferencia ficticia en la que Freud se dispone a hablar de la feminidad como un "enigma" o "misterio" a partir de un "debate entre hombres", según dice en el primer párrafo. En el caso de la escena psicoanalítica, lo que critica Irigaray es la aseveración del carácter primitivo de "la envidia del pene", haciendo aparecer al pene como la representación de la Idea de sexo y a la carencia de pene como el resultado de una castración, entendida 
como una forma de castigo que da cuenta de lo que ella denomina "imperialismo fálico" (Irigaray, 2007: 49). Las mujeres quedan estigmatizadas bajo el rótulo de "histéricas" por su producción de fantasmas, autoerotismos, fingimientos, envidias y atrofias. Para evitar estos padecimientos, Freud recomienda que las mujeres alcancen una feminidad "normal" renunciando a su actividad fálica aunque sea por imitación o réplica. Aquí surge la figura del reemplazo del "deseo del pene" por el "deseo de tener un niño" (62). Aun bajo estas fórmulas todavía subsiste el deseo viril, debido a que la procreación cuando suplanta al pene lo transforma en "hijo-pene". No obstante, las mujeres, de acuerdo a este reemplazo, pasan a ser madres, es decir, mujeres normales que renuncian a su narcisismo. En el caso de los hombres, devenir un hombre "normal" supone renunciar a su deseo edípico de la madre debido a la amenaza de castración. De este modo, se renuncia ficticiamente a la madre para hacer surgir el "ideal de la función materna" (70). Irigaray advierte que la consecuencia de estas suplencias es que las mujeres recubren su sexo en la "idea de mujer" o en la veladura del "eterno femenino" (70). Es importante tener en cuenta que el simbolismo de la castración femenina Freud lo toma de su anatomía, leída como falla originada por un castigo que desconoce la falta cometida, cuyo efecto es una desvalorización de las mujeres en los sistemas de representación sociales y políticos. Irigaray cuestiona la reducción de lo femenino a figura materna, cuya voz suena demasiado "chillona" como para suscitar alguna inquietud en el espacio público. Como puede advertirse, la autora entabla una relación problemática con el patriarcalismo del psicoanálisis y con el falocratismo de la filosofía tras la publicación de este libro. En el caso del psicoanálisis como institución, el efecto fue su expulsión de la École freudienne dirigida por Jacques Lacan. Dejo hasta aquí su libro Espéculo por la amplitud de sus temas. En una entrevista ella misma se refiere a este libro como una "compilación de cuestiones" sobre ese Otro silenciado o borrado por lo Mismo (2009: 89).

Hasta el momento puede parecer que solo se ha hablado de escenas íntimas, en el caso de Freud, lo mismo puede apreciarse en la narración de Platón respecto del mundo de las sombras. Estos temas todavía se mantienen en los supuestos de que la separación entre lo privado y lo público descansa en la apoliticidad de la primera esfera en función de la politicidad de la segunda, así también se lee en Arendt. Habría que preguntarse si esta demarcación no es, acaso, la forma más elevada de patriarcalismo. Si bien Arendt advirtió alguna forma de patriarcalismo en la concepción política de Santo Tomás acerca de la monarquía, su crítica a la figura del padre reside principalmente en que traspasa un dominio o ejercicio despótico del poder que es aceptable en la esfera doméstica pero no en la esfera pública. El padre es, así, un "déspota” cuando actúa del mismo modo privado en lo público, pero Arendt no juzga el despotismo del padre en la esfera doméstica y no advierte las consecuencias políticas de este dominio. A continuación me propongo 
revisar el examen político de Irigaray sobre el amor a partir de su particular lectura de algunos pasajes de la Fenomenología del espíritu de Hegel.

\section{EL AMOR COMO TRABAJO EN HEGEL}

Desde 1981, Irigaray empieza a frecuentar la obra de Hegel. En particular, se preocupa de profundizar la ideología de lo Mismo en la tradición occidental y de desarrollar su propuesta de la diferencia. Bajo este cometido adopta la concepción hegeliana de la ética para desarrollar lo que ella nombra "Ética de la diferencia sexual". Según revela en el prólogo de su libro Amo a ti, publicado en 1992, al leer a Hegel se impacta con el dominio de la conciencia negativa-que ella adjetiva de "masculina"- sobre la naturaleza. En textos posteriores se aprecia que la lectura de Hegel parece estar mediatizada por la perspectiva de Heidegger, el filósofo de la crítica a la racionalidad técnica que también influye poderosamente en Arendt y la motiva a usar el concepto de fabricación. En el caso de Irigaray, así como adjetiva de "masculina" a la conciencia de la que habla Hegel, también dirá que el dominio de la técnica del que habla Heidegger corresponde al de la "subjetividad masculina inconsciente de sí misma” (Irigaray, 1998:91). En lo que respecta a la relación hombre y mujer, ¿de qué dominio se trata? En el contexto de esta relación, que no sería diferente a la relación entre conciencia y naturaleza, se puede empezar por el modo en que ella problematiza el amor entre hombres y mujeres.

"El amor entre nosotros" es el sugerente título de uno de los capítulos del libro Amo a ti. Cronológicamente, este es un libro que se encuentra precedido por La ética de la diferencia sexual, publicado en 1984. Para llegar a explicitar lo que Irigaray entiende por intersubjetividad y por ética es necesario partir por lo que el patriarcado entiende por amor. La perspectiva patriarcal que ella examina en este libro es la de Hegel, recayendo algunas de las responsabilidades del pensamiento de este autor en Marx. El texto comienza evidenciando la ambigüedad de Marx cuando habla de la explotación del hombre por el hombre, ya que reconoce que "la primera explotación humana pasa por la división del trabajo entre el hombre y la mujer" (Irigaray, 1994: 35). En relación a Marx, la pregunta de la autora es la siguiente: “¿Por qué no dedicó su vida a resolver esta explotación?” Según Irigaray, el responsable de que Marx no avanzara en esa dirección es Hegel y su reflexión sobre el amor entendido como "trabajo". Este tema lo desarrolla Hegel principalmente en Fenomenología del Espiritu y en Principios de la filosofía del derecho. El propósito de la lectura de Irigaray es poder pensar y explicitar lo que quedó ensombrecido e impensado respecto de la relación entre hombres y mujeres, a saber: la falta de una relación ética y el predominio de la inmediatez natural. En el lenguaje hegeliano, la "ética" contiene mediaciones culturales que la inmediatez natural no posee. Esta 
falta de ética la habría tomado el autor de las religiones monoteístas, todas de corte patriarcal, que entienden que la sexualidad al interior de la familia queda del lado de la "inmediatez natural" (Irigaray, 1994: 37). Asimismo, debido a su dialéctica, Hegel se habría visto obligado a pensar la relación entre hombre y mujer como "opuestos" y no como "diferentes". Esta oposición entre hombre y mujer acarrea otra: la oposición entre la esfera familiar y el espacio público. De modo semejante a lo sostenido por Aristóteles, en la ciudadanía habría igualdad jurídica válida para ciudadanos abstractos, pero en la familia se permanece sexuados y, por lo tanto, en la inmediatez natural. Al interior de la familia, la mujer comparece como "madre" y "esposa". Bajo estas funciones utilitarias, "corporales" las llama Arendt, las mujeres no pueden singularizarse cuando aman porque ejercen un deber abstracto que las somete a la reproducción. A los hombres, en cambio, se les permite singularizarse cuando regresan al hogar tras ejercer la ciudadanía y su trabajo fuera del hogar. Para la mujer el amor es un "deber" y para el hombre es "una degradación permitida hacia la inmediatez natural" (40). Lo que falta entre ambos es ser "dos". Como se verá, esta es la palabra con la que Irigaray nombra el espaciamiento de la intersubjetividad. La imposibilidad de ser "dos" en el matrimonio o en el amor, supone el encadenamiento de la mujer a un deber universal, careciendo ella misma de una identidad civil. El hombre cumple su deber con el Estado como ciudadano abstracto y vuelve al hogar para descargarse. En este sentido, ambos están absorbidos por un Estado que los instrumentaliza, pero en las mujeres lo que falta es producir una identidad cultural que las saque del apartamiento de lo público, sometidas a las funciones corporales de la maternidad y de la sexualidad patriarcal que las deja sin mediaciones culturales.

Como puede apreciarse, Irigaray es crítica de las propuestas "eruditas" sobre la sexualidad elaboradas por Hegel, Freud y Lacan porque han perpetuado la "incultura" que somete a las mujeres a la violencia de una sexualidad pulsional carente de mediaciones. Incluso, es crítica de la complicidad de las mujeres con la sexualidad y la sociedad del "entre hombres", según llama a lo Mismo, porque las hace imitar las fuerzas mecánicas de la sexualidad cuerpo a cuerpo en abstracto asignada a los hombres en Occidente. Lo descrito hasta el momento sobre la relación entre hombres y mujeres corresponde a la estructura vertical del parentesco, ¿es posible una relación horizontal que suprima el arcaísmo del dominio masculino en la familia y los ideales abstractos de instituciones como el Estado, la Sociedad o el Espíritu? De modo similar a algunas de las exigencias de Arendt respecto de la pluralidad política, Irigaray propone refundar las relaciones humanas, no ya solo entre humanos, sino a partir de una intersubjetividad entre singularidades éticas que no se abstraigan del género, de otro modo la democracia en la que deben cohabitar hombres y mujeres se encuentra en falta. Se trata de una política "mixta" y no solo de la realización de la subjetividad y de la libertad al interior de su 
género. Hoy hablaríamos de una política heterogénea para incluir a las así llamadas minorías sexuales.

\section{LA INTERSUBJETIVIDAD Y LA MEDIACIÓN ÉTICA DEL AMO “A” TI}

Para hablar de intersubjetividad, Irigaray reinterpreta el "ser- con" heideggeriano anteriormente mencionado, y propone otra modulación para experimentar el "entre" de quienes se encuentran en un permanente devenir diferentes. Se trata de que en el ejercicio del amar se derrote la búsqueda de unidad o de fusión para que se exprese el "a ti", es decir, el espaciamiento que permite el encuentro humano como "nosotros" en el contexto de una temporalidad". La "a" de la que habla Irigaray parece ser análoga a la metáfora de la "mesa" empleada por Arendt para hablar de lo común diferenciado de lo unificado, cuyo espacio alude a lo que "está en medio" entre una persona y otra. Arendt explica el significado del "mundo" a través de la imagen de la mesa como modelo para no caer en el despotismo de lo que carece de perspectivas relacionales. Esta última situación la asemeja a una sesión de espiritismo en donde la mesa desaparece y deja a las personas sin separación entre ellas (Arendt, 2001: 62). De modo semejante a la mesa, en el amor la "a" es apreciada como una "barrera" por Irigaray porque impide alienarse en el otro. Sin embargo, al momento de significar el amor es apreciable una discordancia insalvable entre Arendt e Irigaray que repercute en lo que se significa como público y privado. Arendt considera que la pasión en el amor destruye el en medio de que nos relaciona y nos separa. De este modo, no cuestiona que las intencionalidades de quienes lo experimenten puedan llegar a reducirse a una con el peligro de alienarse el uno en el otro. Por el contrario, a Irigaray le importa remarcar la "irreductibilidad" del otro. Por lo tanto, si respeto su alteridad no puedo someterlo ni consumirlo. La "a” es la garantía de la no-inmediatez, de la mediación y la reciprocidad "entre nosotros" (Irigaray, 1994:159). La "a” también impide la reducción del otro a un objeto, imposibilitando que forme parte de mis bienes o propiedades tanto inmateriales como materiales. $\mathrm{Al}$ no poder ser un posesivo, la "a" es una barrera o intervalo que impide que el otro pueda ser alienado o que pueda perder su libertad.

Poco a poco la "a” se presenta como un sustituto de la relación sujeto/ objeto y la del sujeto aislado, cuyo horizonte es siempre una proyección del propio

\footnotetext{
${ }^{8}$ El "a ti” en español es diferente a el "à toi" en francés. Lo que busca remarcar Irigaray con esta fórmula lingüística es la intersubjetividad de la relación entre dos personas mediada por la preposición "a". En Francia, este recurso se usa para las relaciones humanas, descartando la relación entre una persona y un objeto.
} 
yo. Por el contrario, el horizonte del amor así planteado supone establecer una cultura de la diferencia sexual que nos aleja de la sumisión de la sexualidad a la pornografía. Nada de esto podría ocurrir sin un lenguaje que Irigaray califica de "adulto" para modular, desde la autonomía y del respeto por la respiración del otro, una sintaxis que permita hablar-nos según un reparto de las palabras. Un lenguaje comunicacional que no prescinda de la "a", del "entre", del "con" y del "nosotros", establecido sobre la base de lazos, nexos o alianzas que también ayuden a escucharnos. Al igual que Arendt, Irigaray es crítica de la subjetividad introspectiva o pathos del otro, ya que el dolor del otro o su alegría forman parte de un lugar diferente al de la relación (1994: 165). Escuchar al otro no es, pues, la recepción de los sentimientos subjetivos del otro. La horizontalidad exige que en varios aspectos yo no lo comprenda debido a que no es posible apropiarse de la experiencia del otro. Por el contrario, escuchar significa favorecer las emergencias o los devenires del otro. Por este motivo, en este lenguaje y en su escucha se debe incluir el silencio. Permitir el silencio equivale a hacerle saber al otro que nunca será mío porque el nosotros del que se habla aquí jamás podría ceder a la tentación de transformarse en un "todo" (168). Asimismo, este silencio vale para el tocarse, ya que este vínculo se juega en el "tocar a" (176).

Además de ser una barrera o frontera para salvaguardar la alteridad, la "a" permite el "retorno a mí" que en las relaciones abstractas y verticales del matrimonio o amor patriarcal se busca inhibir. Para llegar a "ti" debo antes "girar" en torno de mí. De este modo, la proposición "a” es garante de la intencionalidad y la historia del otro. Irigaray finaliza su reflexión sobre la intersubjetividad con una pregunta similar a la que realiza Arendt en el plano de la pluralidad: "Tú, ¿quién eres?” (170). Podría decirse que se asemejan en lo que concierne al nuevo comienzo al que me entrego cuando tengo una vida política (Arendt). En Irigaray, lo acentuado es el libre devenir. En Arendt son los otros los dicen mi esencia o quién soy yo; a diferencia de Irigaray que prefiere dejar sin respuesta esta pregunta.

Irigaray alude a lo que ella entiende por política de modo más claro en su libro Ética de la diferencia sexual. El advenimiento de esta ética significaría una suerte de "salvación" y cambio de época que transformaría el arte, la poesía, el pensamiento, el lenguaje. Si bien entiende que respecto de las mujeres se han producido aperturas parciales, por lo general se plantean como concesiones y no como un cambio de fundamento de las relaciones humanas. Hoy se divide el mundo de los hombres y el de las mujeres, pero no se piensa ni se declara públicamente el "encuentro" entre los dos sexos. En este sentido, el hombre universal o neutro se escribe y se habla en masculino: es el sujeto del discurso teórico, moral, político, así como el Dios de la religión sigue siendo masculino-paterno. Para Irigaray, el cambio de época hacia la diferencia supondría establecer relaciones diferentes entre hombres, entre mujeres, entre hombre y mundo. En definitiva, el advenimiento de 
dicha época daría lugar al "dos" como una palabra que significa lo múltiple. Pese a no mencionar la homosexualidad y el lesbianismo como formas de amor, Irigaray no reniega de ellas a condición de salvar la diferencia.

Contrariamente a Irigaray, quien se declara "una militante de lo imposible" como "única posibilidad de futuro" (1994: 25), Arendt termina de escribir La condición humana con muy pocas expectativas. No prevé una época futura que permita habitar el mundo de modo plural; más bien constata la victoria de la introspección y de la fabricación procesual en todas sus formas. Para efectos de este artículo, el cometido ha sido ampliar el significado de la pluralidad e introducirlo en la esfera del amor y en el ámbito de los parentescos dominados por los verticalismos del patriarcado. Por lo mismo, ¿no es acaso necesario resignificar y ampliar la palabra relación o entre en todas las relaciones humanas? ¿Acaso podría dejarse fuera de la política al amor, según sostiene Arendt? Recuérdese que las "cuatro paredes" a la que lo relega es para preservar su "encanto" (Arendt, 1993: 61). Esa misma relegación, como sostiene Irigaray, ha permitido las mayores violencias y permitido la proyección fálica del Padre en el resto de las esferas.

Como se puede leer en el artículo, ambas autoras interrogan y resignifican la política asociándola al lenguaje plural o intersubjetivo para salvaguardar la relación entre o relación con otros en contra de la autarquía y del poder totalitario del hombre solitario o introspectivo que actúa como padre, tirano, fabricador y experto en todas las esferas de la interacción humana. Queda abierta la pregunta por una democracia que pueda internalizar las exigencias de la pluralidad en ambas esferas, de otro modo las singularizaciones permitidas por la comunidad política terminarán siendo absorbidas por las exigencias de eficiencia mercantil del experto. Asimismo, la esfera íntima continuará siendo moldeada por las unificaciones abstractas de deberes que son negadores de una ética de la intermediación en las relaciones de género.

\section{REFERENCIAS}

Abensour, Miguel. Hannah Arendt contre la philosohie politique? Paris: Sens \& Tonka éditeurs, 2006.

Arendt, Hannah. La vida delespiritu. Madrid: Centro de Estudios Constitucionales, 1984.

- (Cap. XIII) "Ideología y terror de una forma de gobierno", en Los orígenes del Totalitarismo II. Barcelona: Planeta-De Agostini, 1994. 


\section{--.---.----.-. Entre el pasado y el futuro. Ocho ejercicios sobre reflexión politica.} Barcelona: Ediciones Península, 1996.

La condición humana. Barcelona: Paidós, 2001.

¿Qué es la política? Buenos Aires: Paidós, 2013.

-.---.---.---. Eichmann en Jerusalén. Santiago, Chile: Penguin Random House Grupo Editorial, S.A., 2014.

Benhabib, Seyla. El ser y el otro en la ética contemporánea. Barcelona: Gedisa, 1992.

Birulés, Fina y Fuster, Ángela Lorena. "Prólogo", en Ética de la diferencia sexual. España: Ellago Ensayo, 2010.

Bulo, Valentina. El temblor del ser. Cuerpo y afectividad en el pensamiento de Martin Heidegger. Buenos Aires: Editorial Biblos, 2012.

Butler, Judith. Cuerpos que importan. Sobre los limites materiales y discursivos del "sexo". Buenos Aires: Paidós, 2005.

Dastur, Françoise. "La fin de la philosophie et l'autre commencement de la pensée”, en Heidegger.Questions ouvertes, Revista del Collège International de Philosophie. Paris: Edición Osiris, 1972.

Giannini, Humberto y López, María José. “Comunicación, promesa y política: el poder de las promesas mutuas”, Atenea 509, Primer Semestre, 2014.

Heidegger, Martín. Ser y tiempo, traducción de Eduardo Rivera. Santiago, Chile: Editorial Universitaria, 2005.

Irigaray, Luce. Ser dos. Buenos Aires: Paidós, 1998.

Amo a ti. Buenos Aires: Ediciones de la Flor, 2004.

Espéculo de la otra mujer, traducción de Raúl Sánchez Cedillo. Madrid: Akal, 2007.

--.---.--.-.- "Poder del discurso, subordinación de lo femenino", en Ese sexo que no es uno. Madrid: Akal, 2009. 
-----------. Ética de la diferencia sexual. España: Ellago Ensayo, 2010.

Jonas, Hans. "Actuar, conocer, pensar. La obra filosófica de Hannah Arendt", en Hannah Arendt. El orgullo de pensar, Fina Birulés compiladora. Barcelona: Gedisa, 2000.

Kristeva, Julia. El genio femenino. 1. Hannah Arendt. Buenos Aires: Paidós, 2003.

Nancy, Jean-Luc. Ser singular plural, traducción de Antonio Tudela. Madrid: Arena Libros, 2006.

Nietzsche, Federico. "Segundo Tratado", en La genealogía de la Moral. Madrid: Alianza Editorial, 1995.

Tassin, Étienne. "La phénoménologie de l'action”, en Hannah Arendt. L'humaine condition politique, editado por Étienne Tassin. Paris: L’Harmattan, 2001. 